\title{
A intercooperação nas cooperativas de crédito da região do Vale do Aço: discurso ou efetividade?
}

\author{
Intercooperation in credit cooperatives in the Steel Valley region: speech or \\ effectiveness?
}

\begin{abstract}
Resumo
Intercooperação significa trabalhar em conjunto e, no cooperativismo, esse trabalho conjunto pode intensificar o movimento e servir de forma mais eficiente seus cooperados. Partindo desse pressuposto, neste artigo objetivou-se analisar a prática da intercooperação nas cooperativas de crédito da região do Vale do Aço, na percepção dos gestores. O estudo caracterizou-se como qualitativo e descritivo. Para a coleta de dados utilizouse um roteiro de entrevista semiestruturado. Os partícipes desta pesquisa foram sete dirigentes de três cooperativas definidos pelo critério intencional e acessibilidade. Os resultados indicam que a intercooperação é, ainda, um potencial tímido e pouco explorado nas cooperativas pesquisadas, mesmo evidenciando vantagens e facilitadores que notadamente esse princípio pode trazer para as cooperativas, no que se refere à melhoria de resultados nas atividades conjuntas, ganhos econômico-financeiros com a utilização recíproca de serviços, entre outros. Conclui-se que o discurso desse princípio é muito enfatizado, mas pouco efetivo na sua observância.
\end{abstract}

Palavras-chave: Princípios Cooperativistas; Sistema Financeiro; Gestão Cooperativa.

\begin{abstract}
Intercooperation means working together and, in cooperativism, this joint work can intensify the movement and serve its cooperatives more efficiently. Based on this assumption, this article aimed to analyze the practice of intercooperation in the credit cooperatives of the Vale do Aço region, in the perception of the managers. The study was characterized as qualitative and descriptive. For the data collection, a semi-structured interview script was used. The participants of this research were seven leaders of three cooperatives defined by intentional criteria and accessibility. The results indicate that the intercooperation is still a timid and little explored potential in the cooperatives surveyed, even showing advantages and facilitators that notably this principle can bring to the cooperatives, regarding the improvement of results in the joint activities, economicwith the reciprocal use of services, among others. We conclude that the discourse of this principle is very emphasized, but ineffective in its observance.
\end{abstract}

Keywords: Cooperative Principles; Financial System; Cooperative Management.

Ana Lúcia Magri Lopes ${ }^{\text {I}}$; Edair Costa de Assis ${ }^{\mathrm{II}}$,

ICentro Universitário Unihorizontes, edaircosta@ yahoo.com.br

${ }^{\text {II }}$ Centro Universitário Unihorizontes, ana.lopes@unihorizontes.br 


\section{Introdução}

O cooperativismo brasileiro é atuante em sete ramos, tanto na área rural quanto na urbana, disponibilizando aos seus associados diversos produtos e serviços com substancial diferencial frente às demais empresas. É representado, nacionalmente, pela Organização das Cooperativas Brasileiras

(OCB) e elas organizações estaduais, como a Organização das Cooperativas do Estado de Minas Gerais (OCEMG). Dentre estes, destacam-se as cooperativas que atuam no ramo de crédito objetivando oferecer soluções adequadas às necessidades financeiras de cada associado, além de exercer um papel importante na inclusão financeira das pessoas menos favorecidas, bem como o desenvolvimento econômico e social dos municípios onde se inserem (OCB, 2018).

Conforme anuário divulgado pela OCEMG, em 2017, o Produto Interno Bruto (PIB) do cooperativismo mineiro fechou com $\mathrm{R} \$ 43,3$ bilhões. Ainda, com base no fechamento de 2016, o cooperativismo mineiro apresentou, em todos os ramos cooperativistas, um crescimento de $8,9 \%$ na quantidade de associados e 5,8\% na quantidade de empregados, anterior em relação ao ano. Também em 2016, as cooperativas de crédito apresentaram um crescimento de $20,3 \%$ no patrimônio líquido, $27,4 \%$ no ativo total, $38,6 \%$ no saldo de depósitos e $12,2 \%$ na carteira de empréstimos, em comparação ao ano de 2015 (OCEMG, 2017).

No Brasil, ainda com base no fechamento do anuário de 2016, existiam 6.665 cooperativas de todos os ramos, com 13,2 milhões de associados e 377 mil empregados, sendo 976 cooperativas somente no ramo de crédito, registrando 7,5 milhões de associados e 50 mil empregados. As 768 cooperativas mineiras em todos os ramos, totalizaram 1,5 milhões de associados e 38,2 mil empregados, sendo 190 cooperativas somente no ramo de crédito, somando 1,1 milhões de associados e 9,3 mil empregados. Destaca-se que as cooperativas de crédito estão presentes em $51 \%$ dos municípios mineiros, representando 438 municípios com 723 pontos de atendimentos (OCEMG, 2017).

O cooperativismo é regido por sete princípios, a saber: adesão voluntária e livre; gestão democrática; participação econômica dos membros; autonomia e independência; educação, formação e informação; intercooperação; e, interesse pela comunidade. O sexto princípio, que trata da intercooperação no cooperativismo pode apresentar diversos benefícios para as cooperativas do sistema cooperativista de crédito, dentre eles, a redução de custos e maior escala na conquista de novos negócios e, consequentemente, resultados financeiros satisfatórios (MUNDOCOOP, 2018).

Para Lago (2009), a intercooperação pode ser praticada pela maioria das cooperativas e, com isso, aproveitar ao máximo os benefícios que podem gerar a partir desse princípio cooperativista, principalmente no que se refere às ações conjuntas que fortalecem o cooperativismo. Dessa forma, o desafio que permeia este estudo é responder o seguinte questionamento: Como a adesão ao princípio da intercooperação no cooperativismo de crédito pode influenciar os resultados financeiros das Cooperativas de Crédito da Região do Vale do Aço?

Partindo desse pressuposto, este artigo teve como objetivo analisar a prática da intercooperação nas cooperativas de crédito da região do Vale do Aço, na percepção dos gestores. Ainda, conhecer a adesão ao princípio da intercooperação nessas cooperativas; identificar quais as atividades que podem ser realizadas de forma compartilhada; verificar quais das atividades que se realizadas em conjunto podem melhorar os resultados individuais; e por último e não menos importante, levantar os possíveis ganhos financeiros através das atividades compartilhadas, se realizadas nessas cooperativas.

A ambiência de estudo está relacionada a três Cooperativas de Crédito com sede na Região do Vale do Aço, mais precisamente, nos municípios de Ipatinga e Timóteo no estado de Minas Gerais.

Trata-se de um estudo relevante para o cooperativismo, para a sociedade e para a academia, pois pode contribuir para a disseminação do conhecimento acerca do comportamento e da atuação das cooperativas da referida região no mercado, podendo, ainda, servir como fonte de consulta a outros estudos, dando maior sustentação e visibilidade aos resultados obtidos.

Esta pesquisa está estruturada em seis seções, considerando esta introdução que traz uma contextualização geral do tema. O referencial teórico que trata das temáticas sobre cooperativismo e cooperativismo de crédito e, princípio da intercooperação é apresentado na segunda seção. A terceira 
33 | A intercooperação nas cooperativas de crédito...

aborda a metodologia e, a quarta, a apresentação e análise dos resultados. Na quinta seção as conclusões são ressaltadas, seguida pelas referências utilizadas.

\section{Referencial Teórico}

O referencial teórico contempla as temáticas que versam sobre o Cooperativismo e Cooperativismo de Crédito, e o Princípio da Intercooperação.

\subsection{Cooperativismo e Cooperativismo de Crédito}

A cooperação é percebida desde o início da humanidade, seja nas lutas pela sobrevivência ou nas crises econômicas, políticas e sociais. Conforme Menezes e Lajus (2015), todas as ações ligadas a cooperação anterior ao século XIX, tinham como particularidades uma associação desorganizada e informal com um modelo de ajuda mútua entre os povos rurais de vários países. A cooperação através das pessoas não é novidade, acontece desde a pré-história, sendo averiguada entre as tribos indígenas e antigas civilizações.

O cooperativismo organizou-se de forma mais efetiva e definiu seus principais fundamentos no século XIX em Rochdale, na Inglaterra, com o propósito de originar uma sociedade autossuficiente e que fosse o apoio para outras sociedades que tivessem essa finalidade (SINGER, 2010). Para Marx (2011), o cooperativismo nasceu para fazer frente ao capitalismo industrial baseado na exploração da classe operária e no lucro.

Conforme Ricciardi e Lemos (2000), o conceito do cooperativismo deixa incontestável a maneira mais competente de juntar esforços e recursos, proporcionar melhoria de qualidade de vida dos associados sob suas regras, realizando adequado serviço às suas comunidades participantes. Ainda, o cooperativismo fundamenta-se na solidariedade entre os indivíduos, motivo para ser um mecanismo de promoção humana e não apenas uma ferramenta visando resultado econômico.

Os atuais ramos do cooperativismo são: Agropecuário, Consumo, Crédito, Infraestrutura, Saúde, Trabalho e Produção de bens e Serviços, e Transporte (OCB, 2019), cada um com suas particularidades e desafios específicos do segmento de atuação.

O movimento cooperativista brasileiro foi intensificado por funcionários públicos, militares, profissionais liberais e operários, com o objetivo de suprir suas necessidades (OCB, 2016). Iniciou-se na área urbana e a primeira cooperativa de consumo registrada no Brasil estava alocada na cidade de Ouro Preto - Minas Gerais, em 1889, sob a denominação Sociedade Cooperativa Econômica dos Funcionários Públicos de Ouro Preto que, posteriormente, ampliou para Pernambuco, Rio de Janeiro, São Paulo, Rio Grande do Sul, além de expandir-se no próprio estado de Minas Gerais.

Segundo Santos (2005), em 1902, o Padre Theodor Amstard, missionário que trabalhava com atividades sociais, ao chegar em solo brasileiro, deparou-se com problemas vividos pelos imigrantes alemães que vieram em busca de melhores condições de vida no Brasil, fugindo do desemprego e das dificuldades do seu país de origem. Esses imigrantes encontravam-se aprisionados a agiotas que praticavam juros abusivos e apoderavam-se de suas terras como forma de pagamento de dívidas. Diante deste cenário, iniciou-se o cooperativismo de crédito no Brasil, no estado do Rio Grande do Sul, no município de Nova Petrópolis.

A cooperativa de crédito é uma sociedade constituída por pessoas unidas pela cooperação e ajuda mútua que se organizam para desenvolver programas de assistência financeira e de prestação de serviços, buscando obter o adequado atendimento de suas necessidades econômicas. Segundo Baggio et al. (1983), as cooperativas atuam de forma a excluir os intermediários, reduzir os custos e potencializar os benefícios aos associados. Pinheiro (2008) define cooperativas como instituições financeiras constituídas na forma de sociedade cooperativa, objetivando a prestação de serviços financeiros aos seus associados, a liberação de crédito, depósitos à vista e a prazo, compensação de cheques, serviços de cobrança e custódia, recebimentos e pagamentos, além de outras operações financeiras e atribuições previstas na legislação vigente.

Para Freitas e Freitas (2013), as cooperativas de crédito possuem importância substancial no sistema financeiro, por possibilitar, às pessoas, acesso ao crédito de forma diferenciada em relação às 
instituições bancárias tradicionais, uma vez que as cooperativas atuam com foco no fomento e no desenvolvimento local. De acordo com Hummelgen (2016), a atuação da cooperativa está direcionada às necessidades de seus associados, objetivando o desenvolvimento social da comunidade, apresentando-se como forma viável e próspera para a região onde está inserida.

O Portal do Cooperativismo Financeiro (2016) traz informações sobre os principais sistemas cooperativistas de crédito no Brasil, a saber: SICOOB, SICREDI, UNICRED, CONFESOL e CECRED, entretanto, existem cooperativas independentes, sem qualquer vínculo com esses sistemas. Em alguns países a maior parte dos recursos financeiros é movimentada por uma cooperativa, inclusive, o Banco Francês CreditAgricole figura entre os 50 maiores bancos no mundo. Compreendendo a relevância do cooperativismo para o país, Araújo e Silva (2011) destacam que o governo se dispôs a formular e sancionar leis que possibilitassem o funcionamento e o crescimento do cooperativismo no Brasil. O governo entendeu a importância do movimento para a sociedade e incentivou o trabalho cooperativo entre as variadas classes sociais, objetivando reduzir os impasses de ordem social, econômica, cultural, dentre outras.

Segundo Pinheiro (2008), existem no Brasil, cooperativas de primeiro, segundo e terceiro grau. Aquelas consideradas de primeiro grau são denominadas de singulares e prestam serviços diretamente aos associados, por meio de produtos e serviços visando atender suas necessidades financeiras. As cooperativas de segundo grau são conhecidas como centrais e federações, tendo como objetivo, prestar assistência as suas singulares, atuando como suporte nas demandas, atividades, bem como na utilização dos serviços; sendo constituídas por no mínimo três cooperativas singulares. As cooperativas de terceiro grau recebem a nomenclatura de confederações e são formadas por, no mínimo, três cooperativas centrais e/ou federações de qualquer ramo, que organizam os serviços das suas afiliadas.

\subsection{Princípio da intercooperação}

No cooperativismo, o termo intercooperação significa trabalhar em conjunto, pois é na atuação conjunta que as cooperativas ganham força, intensificam o movimento e servem de forma mais eficiente aos seus cooperados. Quer seja unir em estruturas locais, regionais, nacionais ou até mesmo internacionais, o objetivo gira em torno de um bem comum (OCB, 2018). Segundo Singer (2010), no sistema capitalista as empresas concorrem entre si, gerando resultados sociais poucos satisfatórios, potencializando a precariedade de muitas pessoas, em detrimento de lucros exacerbados.

Benato (1994) já mencionava que a intercooperação é um dos principais princípios do sistema cooperativista, fortalecendo-o e aumentando sua sobrevivência, haja vista que uma cooperativa isolada tem maiores dificuldades de se impor e conseguir melhores resultados.

Conforme descrito no Anuário do Cooperativismo Brasileiro (2018), o movimento de intercooperação somente funciona de forma satisfatória se estiverem envolvidas entidades fortes, bem geridas e com capacidade de se situar no mercado, dialogar e se aprimorar, pensando no coletivo para mais adiante gerar ganhos também no âmbito individual de cada cooperado. A intercooperação é um caminho de mão dupla e compatibiliza as necessidades dos ramos com aquilo que as cooperativas de crédito oferecem (OCB, 2018).

Após a criação da cooperativa, a intercooperação é considerada ponto chave para as cooperativas se organizarem e contribuírem entre si, tendo como propósito favorecer o negócio da cooperativa em prol dos associados (MDIC, 2015). Entretanto, Baggio (2009) aponta a necessidade de maiores informações sobre a prática da intercooperação entre cooperativas, podendo se manifestar através da permuta de produtos e serviços entre duas ou mais cooperativas, constituindo assim, um sistema econômico cooperativo.

De acordo com Jerônimo et al., (2005), a confiança era um dos principais pontos positivos da intercooperação, em que se condenava comportamentos oportunistas e apesar de existir diferença do porte entre cooperativas, todas eram tratadas de maneira igualitária. Rua e Mello (2015) destacam que as organizações que possuem relacionamentos baseados na cooperação, confiança e comprometimento proporcionados pela intercooperação, podem transpor estas dificuldades de forma a obterem vantagens em mercados estrangeiros. 
Para Gaboardi (2012), a intercooperação é capaz de levar os dirigentes das cooperativas, os colaboradores e os cooperados a uma nova forma de pensar sem deixar de lado os princípios do cooperativismo; é fundamental consolidar o potencial econômico, romper velhos conceitos e dar retorno.

A intercooperação é uma estratégia de cooperação entre cooperativas que origina uma associação de interesse privado, de modo a proporcionar benefícios a todas as cooperativas. Apresenta um modelo mais vantajoso em comparação com um cenário onde organizações desempenham atividades de forma independente no ambiente corporativo (BIALOSKORSKI NETO, 2004). A intercooperação pode ocorrer por rede, por centrais ou por consórcios, podendo abarcar diversas atuações do cooperativismo, sendo que os mais comuns são os ramos agropecuário e o de crédito (KONZEN; OLIVEIRA, 2016).

\section{Metodologia}

Nesta seção, são abordadas as questões inerentes ao tipo de pesquisa quanto à abordagem, aos fins e aos meios, juntamente com as unidades de observação e análise, os sujeitos de pesquisa e as técnicas de coleta e análise de dados.

Esta pesquisa de abordagem qualitativa caracteriza-se como descritiva e interpretativa. Segundo Minayo (2005), as pesquisas qualitativas agrupam significados e intencionalidades como intrínsecos aos atos. A pesquisa de caráter descritivo, segundo Triviños (2008), concede ao pesquisador a possibilidade de entender a relação entre o indivíduo e a comunidade estudada por meio do esclarecimento das questões examinadas, enquanto a interpretativa objetiva a interpretação do fenômeno objeto de estudo (SILVA; MENEZES, 2005).

As unidades de observação são três cooperativas de crédito localizadas na região do Vale do Aço, em Minas Gerais. A primeira cooperativa foi fundada em 1966, como cooperativa fechada para funcionários de empresa privada passando a livre admissão, em 2009. Em 2018 contava com 31.790 associados, atuando em 10 municípios com 15 pontos de atendimentos e, no primeiro semestre de 2019, se fez presente em Belo Horizonte, capital de Minas Gerais, através de uma agência compartilhada com outras três cooperativas de livre admissão. A segunda cooperativa foi fundada em 1981, como cooperativa fechada para servidores públicos municipal, estadual e federal. Em 2018 contava com 12.155 associados, atuando em 07 municípios com 07 pontos de atendimentos. A terceira cooperativa foi fundada em 1967, como cooperativa fechada para funcionários de empresa privada. Em 2018 contava com 6.086 associados, atuando em o1 município com 02 pontos de atendimentos. Essas cooperativas atuam com o público pessoa física e pessoa jurídica, mesmo as cooperativas fechadas, pelo fato de ser previsto no estatuto a possibilidade de adesão de empresas ligadas aos associados enquadrados na segmentação de atuação. As sedes dessas cooperativas ficam localizadas num raio de $30 \mathrm{~km}$, concentrando a maior parte dos pontos de atendimentos. Atuam numa região onde a economia predominante é a produção de aço e duas dessas cooperativas tem adotada a estratégia de abertura de pontos de atendimentos em outras praças com ramos de atividades distintos, visando a diversificação dos associados em busca melhores resultados. Já apresentam resultados satisfatório, com boa remuneração do capital dos seus associados, seja através dos juros de capital ou rateio de sobras. Oferecem um grande portfólio de produtos e serviços financeiros, conseguindo atender a maioria das necessidades dos associados, com custos financeiros mais favoráveis, principalmente quando comparados com as práticas bancárias.

A unidade de análise está relacionada com o princípio da intercooperação no cooperativismo de crédito na região do Vale do Aço. Os sujeitos desta pesquisa foram sete dirigentes das três cooperativas supracitadas, codificados de $\mathrm{E}_{1}$ a E7, de forma a mantê-los no anonimato. $\mathrm{O}$ critério de escolha foi intencional por possuírem maior conhecimento sobre suas cooperativas e aos princípios do cooperativismo, podendo gerar maior contribuição para a elucidação do tema proposto e por acessibilidade.

O instrumento de coleta de dados foi um roteiro de entrevista semiestruturado contemplando quinze perguntas abertas relativas à percepção dos entrevistados sobre o princípio da intercooperação no cooperativismo de crédito; a adesão ao princípio da intercooperação pelas 
cooperativas de crédito da região do Vale do Aço; as vantagens da intercooperação para as cooperativas de crédito; as desvantagens da intercooperação para as cooperativas de crédito; os maiores facilitadores percebidos na prática da intercooperação; os maiores dificultadores percebidos na prática da intercooperação; as atividades de intercooperação já implantadas na cooperativa; outras atividades amparadas pelo princípio da intercooperação que podem ser implantadas na cooperativa; as mudanças positivas ocorridas com a intercooperação na cooperativa; as mudanças negativas ocorridas com a intercooperação na cooperativa; se a intercooperação pode afetar os processos na cooperativa; como a intercooperação impacta o planejamento estratégico da cooperativa; como a intercooperação pode tornar a cooperativa mais competitiva; as atividades que podem ser compartilhadas entre as cooperativas de crédito; e, os benefícios financeiros percebidos por meio das atividades de intercooperação na cooperativa. As entrevistas foram agendadas, gravadas e transcritas na íntegra. De acordo com Gil (1999), o roteiro de entrevista semiestruturado é elaborado com perguntas sobre o tema abordado, deixando que o entrevistado responda livremente sem perder o foco.

Os dados foram tratados por meio da análise de conteúdo que, segundo Bardin (2009), compreende um agrupamento de técnicas de análise das comunicações, cuja finalidade é alcançar por meio de procedimentos sistemáticos e objetivos, a definição do conteúdo das mensagens, com fundamentos que possibilitam à dedução de conhecimentos inerentes as condições dessas mensagens.

\section{Apresentação e Análise dos Resultados}

Nesta seção são descritas às análises dos dados apurados na pesquisa, subdivididos de acordo com os objetivos específicos a respeito da adesão ao princípio da intercooperação, atividades de intercooperação na visão dos gestores, atividades conjuntas com expectativas de melhores resultados, e benefícios financeiros com a prática da intercooperação.

\subsection{Adesão ao princípio da intercooperação}

Os princípios cooperativistas, segundo Oliveira (2006), devem ser incorporados pela gestão, contemplados nas ações de planejamento, direção e avaliação das cooperativas, ratificando a importância dos princípios no fortalecimento do cooperativismo. Para Azevedo e Gitahy (2009), a colaboração entre as cooperativas foi incentivada desde o início do cooperativismo e agora existe uma estrutura consolidada de solidariedade financeira, em que a formação de vários fundos viabiliza o apoio às cooperativas em época de crise.

Nessa ótica, a adesão ao princípio da intercooperação, para a maioria dos entrevistados das cooperativas estudadas, faz-se necessária por possibilitar fortalecer esse segmento e abrir novas perspectivas.

[...] A intercooperação entre todos os seus ramos é a chave para a consolidação e crescimento sustentável de todo o cooperativismo e da economia social (E1).

Intercooperação é uma forma de potencializar a prática do cooperativismo, proporcionando a cultura do compartilhamento e ajuda mútua, através dos serviços financeiros às comunidades onde as cooperativas atuam. As cooperativas se ajudam mutuamente, compartilham soluções e oferecem à comunidade um serviço que prima pela excelência $\left(\mathrm{E}_{2}\right)$.

Para os entrevistados, a intercooperação consiste na essência do crescimento sustentável e age como forma de potencializar o cooperativismo, sendo fundamental para qualquer ramo, especificamente o de crédito, por ter mais facilidade em praticar a intercooperação, haja vista o amplo relacionamento entre as cooperativas. 
O princípio da intercooperação em qualquer ramo do cooperativismo é fundamental. Alguns ramos têm mais facilidade de desenvolver essa intercooperação. No ramo de crédito, devido ao amplo relacionamento, também demonstra essa facilidade, podendo trazer benefícios para todas as cooperativas (E6).

Para Konzen e Oliveira (2016), a intercooperação pode se manifestar através de redes, centrais e consórcios, podendo abranger diversos segmentos do cooperativismo. Para um dos entrevistados, a intercooperação é o futuro do cooperativismo, tanto para os associados, como para as cooperativas. É uma forma de se praticar a solidariedade, a inclusão financeira, expansão do cooperativismo e combate às desigualdades sociais.

A intercooperação é o futuro do cooperativismo. Essa é a sexta linha orientadora do cooperativismo e trata da parceria e ajuda mútua não somente entre associados, mas também entre as cooperativas locais, regionais, nacionais ou internacionais, sejam do mesmo ramo ou não. Essa é mais uma das formas pelas quais se pratica a solidariedade, que é uma das bases do sistema cooperativista. É um dos movimentos em favor da inclusão financeira, do fortalecimento e expansão do cooperativismo financeiro, instrumento do desenvolvimento local sustentável e de combate às desigualdades sociais e regionais $\left(\mathrm{E}_{7}\right)$.

Para Alves (2007), os eventos que envolvem a sociedade estão de alguma maneira, ligados aos princípios cooperativistas, visto que o sétimo princípio é definido como interesse pela comunidade. Ricciardi e Lemos (200o), relatam que o cooperativismo tem como base a solidariedade entre as pessoas, motivo para ser um instrumento de promoção humana e não simplesmente uma estrutura em busca de resultados econômicos.

As cooperativas servem de forma mais eficaz os seus membros e dão mais força ao movimento cooperativo, trabalhando em conjunto, através das estruturas locais, regionais, nacionais e internacionais. Se os associados se ajudam mutuamente, as cooperativas deverão fazer o mesmo. Só assim haverá um crescimento econômico, cultural e social dos associados e do Sistema Cooperativista (E5).

Para alguns entrevistados as cooperativas devem evitar a concorrência agressiva entre elas, destacando o fato de representarem uma única marca. Além disso, se os associados se ajudam mutuamente, as cooperativas podem fazer o mesmo. Dessa forma evidencia-se, pelos relatos dos entrevistados, que a intercooperação nas cooperativas estudadas apresenta certa fragilidade evidenciada pela carência de ajuda mútua. Um dos entrevistados declara que não existe a intercooperação entre as cooperativas.

Em minha opinião não existe, as cooperativas se relacionam como concorrentes e esquecem que os nossos concorrentes são os bancos privados e estatais $\left(\mathrm{E}_{1}\right)$.

Entendo que devemos trabalhar em conjunto sem concorrência agressiva entre as cooperativas, temos que entender que somos vistas pelo público como uma única instituição, assim não devemos criar dificuldades para atender cooperados de outras cooperativas, nos pagamentos, nos saques intercredis e outros serviços possíveis de serem realizados fora da agência de origem. Temos que ter em mente que somos uma única marca (E3).

A intercooperação acontece quando as cooperativas atendem seus cooperados efetivamente, fortalecem o movimento cooperativista e quando trabalham em conjunto por meio de estruturas 
locais, nacionais, regionais e internacionais (ICA, 2015). Hummelgen (2016) acrescenta que as ações das cooperativas precisam estar alinhadas às necessidades dos associados, realizando o desenvolvimento social e melhoria da região.

Apesar da conscientização dos entrevistados acerca da importância da adesão das cooperativas ao princípio da intercooperação, essa prática não é percebida. As cooperativas se relacionam como concorrentes intercooperando basicamente pelos canais eletrônicos, além de praticarem a rivalidade, buscando conquistar cooperado de outra cooperativa, desrespeitando a sua área de atuação.

A intercooperação acontece basicamente na utilização da movimentação intercredis, ou seja, cooperados de uma cooperativa utilizam canais eletrônicos de outra cooperativa (E2).

$\mathrm{Na}$ verdade, estamos engatinhando neste sentido, existe muita rivalidade entre as cooperativas, ainda existe cooperativa querendo tirar cooperado de outra, invadir a área de atuação, desrespeitando o princípio da cooperação mútua (E3).

Conforme Lago (2009), as recorrentes invasões de áreas de atuação entre as cooperativas, gera um ambiente de indignação e acirrada concorrência, o que inibe as ações de intercooperação. Baggio (2009) complementa que existem poucas informações sobre a prática da intercooperação e o que se sabe é que não acontece em grande escala.

Contrariando o relato de outros entrevistados, observa-se pelo relato de um dos entrevistados, a existência da prática da intercooperação nas cooperativas da região do Vale do Aço, porém alguns fatores como a resistência, as diferenças culturais e o excesso de competitividade dificultam a adesão dessas cooperativas ao princípio da intercooperação. Na perspectiva de Lago (2009), as diferenças financeiras, culturais, produtivas, profissionais, regionais, entre outras, são aspectos que prejudicam a intercooperação.

O princípio da intercooperação é sempre praticado entre as cooperativas do Vale do Aço, porém existe ainda muita resistência, acredito que seja devido há alguns fatores os quais podemos destacar as diferenças culturais e excesso de competitividade $\left(\mathrm{E}_{7}\right)$.

Para Bertolin et al. (2008), o quesito confiança se destaca nas instituições como elemento essencial ao nível de adesão e comprometimento de seus participantes; no caso de alianças cooperativas, a confiança é fundamental, principalmente pelas características específicas do sistema cooperativista.

As vantagens da intercooperação percebidas nessas cooperativas estão relacionadas com a abrangência das ações, redução de custos com as manutenções e aquisições conjuntas, além de maior credibilidade, confiança e rentabilidade das cooperativas.

Maior amplitude e abrangência das ações das cooperativas, com redução de custos nas ações compartilhadas (E2).

Credibilidade, confiança entre os cooperados e aumento da rentabilidade financeira das cooperativas $\left(\mathrm{E}_{4}\right)$.

São inúmeras, uma delas é buscar objetivos comuns e desenvolver ações que podem ser feitas para uns e para outros, dando mais dinâmica e eficiência nos processos e reduzindo seus custos (E6).

Os motivos de constituir um relacionamento pela intercooperação estão no ganho de escala, poder de barganha, redução de custos, inovações e instabilidade econômica (LAGO, 2009). Além disso, o comprometimento, a transparência, a confiança e a eliminação de vaidades, são requisitos para a prática da intercooperação. 
Quanto às desvantagens da intercooperação, a maioria dos entrevistados desconhece essa questão e aludem a confiança e a lealdade entre as partes como a base desse princípio. Mas, enfatizam essa possibilidade caso seja utilizada para outros fins.

Não vejo desvantagens desde que haja confiança e lealdade das partes $\left(\mathrm{E}_{3}\right)$.

Possíveis desvantagens somente se os gestores utilizarem a intercooperação para outros fins (E6).

Segundo Jerônimo et al. (2005), a confiança é um dos principais quesitos da intercooperação, onde se rejeitava comportamentos oportunistas, tratando com igualdade mesmo as cooperativas de portes diferentes. O relato do entrevistado deixa claro, a importância da prática da intercooperação, uma vez que a não observância desse processo pode levar o sistema cooperativista ao desaceleramento devido ao cenário econômico e competitivo em que se encontra.

Na minha visão não vejo desvantagens neste processo, muito pelo contrário, se não houver este processo o mais rápido possível estaremos fadados à desaceleração do sistema cooperativista, devido ao cenário econômico e mercado competitivo em que vivemos (E1).

Segundo Jerônimo et al. (2005), as cooperativas veem como desvantagem a perda de propriedade individual da informação, tendo que ser compartilhada com outras cooperativas participantes. Para Frantz (2003), a cooperação pode ser vista como um processo de mudança, positivo ou negativo, que gera desenvolvimento econômico e melhorias de condições, sob todas as suas extensões, a todos os envolvidos.

Sobre os facilitadores para a intercooperação, o apoio das centrais e da confederação, o espírito cooperativista, a proximidade geográfica, e a diversificação dos ramos de atuação, foram os mais enfatizados pelos entrevistados.

Proximidade geográfica, diversificação dos ramos de atuação das cooperativas, reserva orçamentária prevista com antecedência pelas cooperativas, divulgação do Sistema Cooperativista $\left(\mathrm{E}_{5}\right)$.

Como dificultadores para a intercooperação os entrevistados destacaram a falta de visão administrativa e econômica, a falta de comunicação, a competição existente entre as cooperativas e os trabalhos realizados de forma isolada.

A falta de visão holística dos gestores, tanto no âmbito administrativo quanto nos cenários econômicos (E1).

Falta de comunicação entre cooperativas, falta de planejamento de ações conjuntas, competição entre cooperativas localizadas na mesma área de atuação (E2).

Trabalho isolado, causando a não integração e afetando o crescimento do sistema Sicoob $\left(E_{4}\right)$.

Para Benato (1994), o princípio da intercooperação é um dos principais do sistema cooperativista, fortalecendo e alimentando a sua própria sobrevivência, visto que uma cooperativa não possui condições de se impor e obter melhores resultados, atuando isoladamente. Segundo Oliveira (2006), os fatores que devem inspirar as lideranças nas cooperativas são a supervisão, a motivação, o treinamento, a comunicação, a administração participativa e o comprometimento.

Além disso, na visão de alguns entrevistados, os dificultadores estão relacionados com a demora na tomada de decisão, falta de governança, diferenças culturais, perda de autonomia, inadequada capacitação, individualismo e oportunismo, entre outros. 
Demora na tomada de decisão; ausência de estrutura de governança, ausência de projeto estruturado (E5).

As dificuldades estão nas pessoas, nos gestores e dirigentes das cooperativas, com comportamentos de vaidade e egoísmo, e que não combinam com o cooperativismo (E6).

[...] diferenças culturais, o medo da perda de autonomia, a falta de confiança, a competição entre organizações e as diferenças no modo como os gestores tratam a intercooperação. Apesar das cooperativas terem na sua essência o princípio de cooperar, o individualismo e o oportunismo ainda se fazem presentes $\left(\mathrm{E}_{7}\right)$.

Bialoskorski e Gomes (2010) enfatizam que um dos dificultadores que podem acontecer com a intercooperação é a perda de poder decisório, caráter democrático natural do cooperativismo. Dutra (2010) descreve que para maior rapidez na tomada de decisão é essencial que tenha um planejamento conjunto, possibilitando o conhecimento e o posicionamento dos objetivos comuns.

$\mathrm{Na}$ percepção dos entrevistados, a intercooperação pode impactar o planejamento estratégico, através da definição de uma estrutura adequada para atender o público de todas as cooperativas na região. Elaboração do plano conjunto visando reduzir custos e despesas. Contribuição na análise da visão macroeconômica e tendências de mercado. Facilitando atingir as metas propostas no planejamento estratégico.

É preciso conhecer a atuação das outras cooperativas próximas, para definir a estrutura para atender ao público da nossa cooperativa e também destas outras, cujos cooperados serão atendidos por nós; Definição de plano de divulgação conjunta de produtos e serviços, com custo reduzido em função do rateio das despesas (E2).

O Planejamento Estratégico é uma ferramenta de gestão indispensável nas instituições em consonância com o orçamento para o exercício vigente. Assim, os recursos destinados a ações de Intercooperação deverão estar previstos no Planejamento estratégico e no orçamento de forma a não impactarem nas despesas da instituição $\left(E_{5}\right)$.

Numa visão macroeconômica e tendências de mercado, a intercooperação poderá contribuir. Podendo ser um dos pontos de atenção na elaboração do planejamento estratégico (E6).

Segundo Woitchunas (2009), os principais benefícios com o planejamento estratégico referem-se a ganhos de credibilidade, importância da cooperativa em seu ambiente comercial, valorização da marca, marketing compartilhado, redução de custos, redução dos riscos, capacitação gerencial, qualificação profissional, novos conceitos, métodos e estilo de gestão, além da troca de informações e experiências.

\subsection{Atividades de intercooperação na visão dos gestores}

Nesta seção são descritas as atividades amparadas no princípio da intercooperação que, na visão dos gestores, podem ser realizadas de forma compartilhada.

As atividades de intercooperação já implantadas conforme relato dos entrevistados estão relacionadas com a troca de informações, compartilhamentos de processos e manuais, atendimento a cooperados de outras cooperativas, contratação de serviços de empresas cooperativas, parcerias de negócios com cooperativas de outros ramos, utilização do apoio da central de cooperativas facilitando os processos e as atividades cooperativistas, além de reuniões e treinamentos. $\mathrm{E}$ ainda, as 
atividades promovidas pela organização estadual das cooperativas. Com isso, percebe-se que já existem diversas atividades nessas cooperativas baseadas na intercooperação.

Temos um relacionamento bem definido com cooperativa de outra região, com troca de informações, compartilhamento de processos e manuais internos $(\mathrm{E} 1)$.

O Dia "C", com adesão de cooperativas dos diversos ramos, o que favorece a aproximação e oferta de condições diferenciadas nesta parceria. Utilização de caixa automático, Comercialização de planos de Saúde de Cooperativa Médica (E2).

Procuramos atender aos cooperados do sistema SICOOB independente da cooperativa que são associados, também apoiar outras cooperativas quando somos procurados, temos por hábito de contratar serviços de cooperativas prestadoras de serviço sempre que possível, mas acho que poderíamos ser mais unidos ( $\left.\mathrm{E}_{3}\right)$.

Antunes, Balestrin e Verschoore (2010), apontam que as oportunidades de aprendizagem e inovação, acontecem mediante troca de ideias e de experiências, além disso, as ações conjuntas potencializam o desenvolvimento de produtos, processos e serviços inovadores.

Como outras atividades, entendidas como importantes pelos gestores e amparadas pelo princípio da intercooperação, que podem ser implantadas nas cooperativas, os entrevistados relatam sobre o relacionamento das cooperativas da região, respeitando os seus segmentos de atuação. Sistemas tecnológicos com custos inferiores aos atuais. Reuniões entre os dirigentes das cooperativas da região. Atividades conjuntas como eventos regionais, agências compartilhadas, e outras atividades. Além da qualificação profissional e padronização de processos. Assim, pode-se evidenciar que ainda existem atividades a ser incrementadas com base na intercooperação.

Melhorar o relacionamento com as cooperativas da região, respeitando os seus segmentos $(\mathrm{E} 1)$.

Ações de divulgação, de marketing, projetos sociais, eventos regionais, agências compartilhadas, caixas automáticos compartilhados, incorporações de cooperativas (E2).

Reuniões entre o corpo de gestão, aquisição de equipamentos, desenvolvimento de sistema auxiliar ao SISBR (E4).

Tem várias atividades que podem implantadas, dentre elas: segurança, tecnologia, seleção de pessoas, comunicação e publicidades (E6).

As atividades relevantes que podem ser compartilhadas, na visão dos entrevistados, são diversas, dentre elas: suporte operacional, comunicação, publicidade, segurança, recrutamento e seleção de pessoas. Ainda, serviços contábeis, consultorias, e aquisições de materiais e equipamentos. Também, serviços de terceiros, elaboração de projetos, e gestão de patrimônio. Percebe-se que existem várias oportunidades para compartilhar as atividades nas cooperativas.

Plano de divulgação e Marketing; Participação em feiras e eventos; Desenvolvimento de projetos sociais e envolvimento com as comunidades; Incorporação de cooperativas; Contabilidade; Gestão de Patrimônio, manutenção de sistema, Contratação de terceiros: Vigilantes, Monitoramento e Serviços gerais (E2).

Como início, acho que deveríamos trabalhar o compartilhamento das aquisições de materiais, equipamentos, serviços de terceiros como consultorias, treinamentos de equipe, e à medida que as atividades 
implantadas forem sendo sedimentadas abriríamos o leque para outras atividades $\left(\mathrm{E}_{3}\right)$.

Aquisição em grande escala de quaisquer produtos e serviços comuns, o volume diminui o preço. Ações coordenadas de responsabilidade social e Comunicação (E5).

Para Antunes, Balestrin e Verschoore (2010), a negociação conjunta pode assegurar um poder de barganha devido seu nível de representatividade, proporcionam acordos comerciais em condições diferenciadas. É possível diminuir custos diversos como aluguel, telefonia, logística, manutenção e outros.

\subsection{Atividades conjuntas com expectativas de melhores resultados}

Na percepção da maioria dos gestores entrevistados, a prática da intercooperação pode tornar a cooperativa mais competitiva através do alinhamento de processos e da capacidade de desenvolver cenários promissores, possibilitando maior visibilidade ao portfólio de negócios e maior envolvimento com a comunidade onde está inserida.

Dando maior visibilidade ao portfólio de negócios, atuando mais fortemente em projetos sociais, demonstrando a preocupação e envolvimento com a comunidade e melhoria da qualidade de vida dos cooperados (E2).

Além disso, alguns gestores enfatizaram que as atividades compartilhadas podem resultar em agilidade, redução nos custos, fortalecimento da marca e da imagem das cooperativas e solidez no sistema cooperativista.

Um dos entrevistados, entretanto, associa a prática da intercooperação à colaboração que, de certa forma, beneficia os cooperados, não tendo relação direta com questões voltadas para a competitividade.

Não percebo ação de competitividade e sim de colaboração em prol de um bem maior que são os cooperados $\left(E_{5}\right)$.

Existem diferentes possibilidades para gerar maior competitividade para as cooperativas no mercado financeiro. Jerônimo (2005) já mencionava que a rede está associada a objetivos estratégicos como, aumentar a participação em novos mercados e nos mercados existentes, incrementar o poder de compra através de negociações de redução de custos, maior poder no mercado de atuação em função do peso econômico, expansão da base técnica com atividades de pesquisa e desenvolvimento e maior conhecimento através de aprendizagem coletiva.

Também na visão da maioria dos entrevistados, a intercooperação poderá afetar os processos das cooperativas de maneira positiva, com uma melhor integração entre as cooperativas, atuando com uma política de troca de experiências operacionais.

Somente de maneira positiva, através de uma política de recursos humanos, experiências operacionais, treinamentos em conjunto, qualquer coisa ao contrário é a falta de trabalho com intercooperação (E6).

De outra forma, alguns entrevistados deixam transparecer certa preocupação devido ao desconhecimento dos cooperados ou potenciais cooperados sobre as especificidades do funcionamento do sistema cooperativista.

Processos como aquisição, manutenção, e suprimento de caixa automático são alterados em função da demanda de cooperados de outras cooperativas (E2). 
Devido à falta de conhecimento de como funciona o sistema cooperativo, os cooperados ou possíveis cooperados podem não diferenciar as cooperativas $\left(\mathrm{E}_{7}\right)$.

Assim, os discursos dos entrevistados apontam para algumas potencialidades, mas também fragilidades nos processos de intercooperação nas cooperativas. Todavia, Barcellos e Ferreira (2006) consideram que as atividades conjuntas refletem resultados positivos por meio de melhorias de qualidade, redução de tempo de chegada do produto ao mercado, melhoria na distribuição de produtos e matérias primas, não visualizando resultados negativos nesse processo.

\subsection{Benefícios financeiros com a prática da intercooperação}

Os benefícios financeiros percebidos pelos entrevistados, por meio da prática da intercooperação, estão relacionados com a redução de custos, aquisição conjunta de bens e equipamentos, ampliação das receitas com o aumento dos negócios e conquista de mais cooperados.

Poderíamos ter benefícios com maior eficiência na aquisição de bens de consumo e equipamentos (E3).

Aumento da rentabilidade financeira com a redução de custos, comercialização de produtos e a utilização dos cooperados nas outras cooperativas $\left(\mathrm{E}_{4}\right)$.

O maior benefício na relação custo versus benefício é a aquisição em escala, que reduz drasticamente as despesas das cooperativas (E5).

Ampliação da receita através do fortalecimento da marca no mercado, com conquista de mais cooperados e aumento dos negócios. Repasse de experiências que podem contribuir para gerar redução de custos e melhores resultados (E6).

Sendo assim, os entrevistados sinalizam diversos benefícios financeiros para as cooperativas com a adesão e prática da intercooperação. Segundo Macedo e Moraes (2009), os incentivos aos participantes são oriundos de ganhos econômicos proporcionados pela coordenação do líder. A liderança atua mediante a coordenação vertical a partir de seus objetivos estratégicos, que estabelecem o conjunto de incentivos e obrigações aos demais participantes. Para Barringer e Harrison (2000), as iniciativas interorganizacionais vêm sendo praticadas com relativo sucesso, pois ajudam a superar limitações em termos de recursos, capacidades e competências essenciais através do trabalho conjunto.

\section{Conclusões}

Os resultados evidenciam que nestas cooperativas uma maior adesão ao princípio da intercooperação faz-se necessária, por fortalecer o segmento de crédito e abrir novas perspectivas para o ganho em escala, maior eficiência, solidariedade e inclusão financeira da comunidade. Além disso, a prática da intercooperação deve ser intensificada, devido à pouca existência de ajuda mútua entre essas cooperativas, apesar da conscientização dos entrevistados acerca da importância da adesão das cooperativas ao princípio da intercooperação na região onde estão inseridas. Demonstram pouca vivência na prática da intercooperação, principalmente nos relatos de alguns entrevistados quando destacam fatores como a diferença cultural e a forte concorrência entre elas.

Os dados apontam que a adesão ao princípio da intercooperação nestas cooperativas ocorre em partes, corroborado pelos relatos de entrevistados que ocorrem somente nos canais eletrônicos e que estão em uma fase embrionária nesse sentido, além de existir muita rivalidade. De maneira positiva, evidenciam diversas atividades com possibilidades de serem realizadas de forma 
compartilhada, podendo destacar a utilização de espaço cooperativo, ações de marketing, seleção de pessoal, serviços contábeis, gestão de patrimônio, dentre outras.

Percebe-se que a prática da intercooperação pode gerar cenários mais promissores, contribuindo para que algumas atividades possam gerar melhores resultados se comparadas com uma execução individual, podendo resultar em maior agilidade e no fortalecimento da imagem das cooperativas, sendo citado como principais à troca de experiências, treinamentos, aquisição e manutenção de equipamentos. Também são percebidos diversos benefícios financeiros com a prática da intercooperação, tendo maior ênfase a redução de custo de aquisições em maior escala, a ampliação da receita através das ações comerciais conjuntas e na conquista de mais associados. Benefícios financeiros que são revertidos aos associados por meio dos juros ao capital e pela distribuição de sobras anuais.

Os resultados indicam vantagens com a intercooperação, sendo destacados diversos facilitadores como a proximidade geográfica, apoio da central e da confederação. Mas também, alguns dificultadores relacionados à falta de comunicação e excessiva concorrência entre as partes, que necessitam ser tratados previamente para não comprometerem de forma negativa a boa prática de intercooperação. Além de a intercooperação poder contribuir na definição do planejamento estratégico, com diversas atividades que podem ser realizadas em conjunto, amparadas por esse princípio, podendo citar o suporte operacional, publicidades, segurança e sistema tecnológico.

Essas evidências contribuem para o avanço da intercooperação nas cooperativas estudadas, podendo contribuir também para outras cooperativas, independentemente do ramo de atuação. Visto que, estão abertas à prática da intercooperação, que identificam benefícios que podem ser conquistados e reconhecem a intercooperação como o futuro do cooperativismo e a base para o crescimento sustentável. Apontam desvantagens e dificuldades tais como existência de paradigmas, falta de confiança, demora na decisão, individualismo e oportunismo, que poderão ser sanadas com o envolvimento dos dirigentes e alinhamento de procedimentos, reativando a confiança que em algum momento foi fragilizada. Dessa forma, pode-se concluir que a prática da intercooperação nestas cooperativas está mais para discurso do que para efetividade.

A principal contribuição deste estudo consiste em demonstrar a importância de se pensar a prática da intercooperação nas cooperativas pesquisadas, frente às dificuldades apontadas e que aparentemente, não são impossíveis de serem superadas.

As limitações desta pesquisa estão relacionadas com a dificuldade de envolver todos os sujeitos na participação da pesquisa, sendo necessário realizar diversos contatos e, na maioria das vezes, agir de forma insistente. Além da questão de serem cooperativas diferentes, necessitando de deslocamento e dificultando ainda mais o agendamento das entrevistas.

É recomendável estudos futuros, com uma possível ampliação do número de sujeitos pesquisados, para que possa validar os resultados desta pesquisa e poder verificar evidências diferentes daquelas encontradas neste presente momento. Além de permitir levantar a evolução da prática da intercooperação nestas cooperativas a partir deste estudo.

\section{Agradecimentos}

Agradecemos aos revisores, aos colaboradores, aos representantes das Cooperativas participantes desta pesquisa, a Central dessas Cooperativas no Estado de Minas Gerais e a Organização das Cooperativas do Estado de Minas Gerais, por terem apoiados a realização desse estudo.

\section{Referências}

ALVES, R. Filosofia da ciência: introdução ao jogo e suas regras. São Paulo: Loyola, 2007, 249p.

ANTUNES, J.; BALESTRIN, A.; VERSCHOORE, J. Práticas de gestão de redes de cooperação. São Leopoldo: Editora Unisinos, 2010. 
ARAÚJO, E. A. T.; SILVA, W. A. C. Sociedades Cooperativas e sua Importância para o Brasil. Revista Alcance - Eletrônica, v. 18 - n. 1 - p. 43-58 / jan-mar 2011.

AZEVEDO, A.; GITAHY, L. Corporación Cooperativa Mondragón MCC: cooperativismo, autogestão e competitividade. http://inovacao.scielo.br/pdf/inov/v2n4/a23vo2n4.pdf. Acesso em 2009.

BAGGIO, A. F. et al. Elementos de Cooperativismo e Administração Rural. Ijuí: FIDENE, 1983. 192p.

BAGGIO, A. F. Estratégias de cooperação e relações associativistas - Ijuí: Ed. Unijuí, 2009 - 98p.

BARCELLOS, M. D.; FERREIRA, G. C. Vantagens e desvantagens das alianças estratégicas: uma análise sob a ótica dos agentes da cadeia produtiva da carne bovina. Organizações Rurais \& Agroindustriais, v.8, n.1, p.117-130, 2006.

BARDIN, L. Análise de Conteúdo. Lisboa: Edições 70, 2009, 281p.

BARRINGER, B. R.; HARRISON, J. S. Walking a tightrope: creating value trough interorganizational relationships. Journal of Management, Stillwater, v. 26, n. 3, p. 367-403, 2000.

BENATO, J. V. A. O ABC do cooperativismo. São Paulo: ICA-OCESP, 1994. 131p.

BERTOLIN, R.V.; SANTOS, A.C.; LIMA, J.B. et al. Assimetria de informação e confiança em interações cooperativas. Revista Administração Contemporânea, v.12, n.1, p.59-81, 2008.

BIALOSKORSKI NETO, S. Economia das organizações cooperativas: uma análise da influência da cultura e das instituições. Faculdade de Economia, Administração e Contabilidade de Ribeirão Preto, Universidade de São Paulo, Ribeirão Preto, 2004.

BIALOSKORSKI NETO, S.; GOMES, C. B. Um ensaio sobre os desafios da intercooperação entre cooperativas agropecuárias no Brasil. In: Encontro Brasileiro de Pesquisadores em Cooperativismo (EBPC). 1. 2010. Anais. Brasília: 2010.

DUTRA, J. N. A intercooperação como processo de desenvolvimento: um caso de cooperativas articuladas em rede. Ijuí: 2010.

FRANTZ, W. Caminhos para o desenvolvimento pelo cooperativismo. Biblioteca Universitária Mario Osório Marques - Unijuí. Ijuí, 2003.

FREITAS, A.; FREITAS, A. F. O cooperativismo de credito no Brasil e a emergência de uma vertente solidaria. Anais... XXXVII Encontro do Anpad. Rio de Janeiro, RJ, 7 a 11 de setembro de 2013.

GABOARDI, R. B. A intercooperação e seus resultados diante do panorama do cooperativismo agropecuário Paranaense. Curitiba, 2012. Disponível em: https://acervodigital.ufpr.br/.../R\%20\%20E\%20-\%2oRENATA\%2oBORDIGNON\%2. Acesso em 18 set 2018.

GIL, A. C. Métodos e técnicas de pesquisa social. São Paulo: Atlas, 1999.

HUMMELGEN, B. Cooperativismo: um agente de mudança. Maringá: Revista Urutágua, 2016. p. 7476.

INTERNATIONAL CO-OPERATIVE ALLIANCE - ICA. Co-operative identity, values \& principles. Disponível em: https://www.ica.coop/en/cooperatives/cooperative-identity. Acesso em: 13 set 2015.

JERÔNIMO, F. B.; PEDROZO, E. Á.; FENSTERSEIFER, J. E.; SILVA, T. N. Rede de Cooperação e Mecanismos de Coordenação: A Experiência da Rede Formada por Sete Sociedades Cooperativas no Rio Grande do Sul. Ribeirão Preto: 2005. Disponível em: http://www.sober.org.brpalestra2984.pdf. Acesso em 15 ago de 2018.

JERÔNIMO, F.B. A confiança em redes: a experiência de uma rede formada por sete cooperativas do setor agroalimentar no Rio Grande do Sul. 173f. 2005. Dissertação (Mestrado) CEPAN/Universidade Federal do Rio Grande do Sul, Porto Alegre. 
KONZEN, R. R. P.; OLIVEIRA, C. A. Intercooperação entre cooperativas: barreiras e desafios a serem superados. Revista de Gestão e Organizações Cooperativas, v. 2, n. 4,p. 45-58, 2016. http://dx.doi.org/10.5902/2359043220410.

LAGO, A. Fatores Condicionantes do Desenvolvimento de Relacionamentos Intercooperativos no Cooperativismo Agropecuário. Porto Alegre: 2009. Disponível em: https://www.researchgate.net/profile/Lago_Adriano/publication/277761904. Acesso em o5 dez 2018.

MACEDO, L. O. B.; MORAES, M. A. F. D. Perfil de governança e a coordenação de alianças estratégicas do sistema agroindustrial da carne bovina brasileira. 2009. 203f. Tese (Doutorado)

- Escola Superior de Agricultura "Luiz de Queiroz"/Universidade de São Paulo, Piracicaba.

MARX, K. O Capital: crítica da economia política: livro primeiro: o processo de produção do capital. 29 ed. Rio de Janeiro: Civilização Brasileira, 2011. v. 1.

MENEZES, C. M.; LAJUS, M. L. de S. Cooperativismo de Crédito e Desenvolvimento. Revista Economia e Desenvolvimento, v.14, n.2, 2015. p. 294-313.

MINAYO, M. C. de S. (Org.). Pesquisa Social: teoria, método e criatividade. 29. ed. Petrópolis: Vozes, 2005. 108 p.

MINISTERIO DO DESENVOLVIMENTO, INDÚSTRIA E COMERCIO EXTERIOR (MDIC). Intercooperação, Conceitos e Definições. Disponível em: http://www.mdic.gov.br/sistemas_web/aprendex/cooperativismo/index/conteudo/id/317. Acesso em: 15 maio 2018.

MUNDOCOOP. Informação e inspiração para o cooperativismo. 2018. Disponível em http://www.mundocoop.com.br/cooperativismo/o-que-e. Acesso em 13 dez 2018.

OCB - Organização das Cooperativas Brasileiras. Disponível em: http://www.ocb.org.br/site/cooperativismo/principios.asp. Acesso em: o1 out 2018.

OCB - Organização das Cooperativas Brasileiras. Anuário Brasileiro do Cooperativismo 2018/2019, p. 18, 28 e 79. Disponível em: www.mundocoop.com.br. Acesso em 18 set 2018.

OCB - Organização das Cooperativas Brasileiras 2019. Disponível em: http://www.ocb.org.br/ramos. Acesso em: 26 abr 2020.

OCEMG - Organização das Cooperativas do Estado de Minas Gerais. Anuário do Cooperativismo Mineiro 2017. Disponível em: www.minasgerais.coop.br. Acesso em 18 set 2018.

OLIVEIRA, D. P. R. de. Manual de gestão das cooperativas: uma abordagem prática. 3 ed. São Paulo: Atlas, 2006.

PINHEIRO, M. A. H. Cooperativas de Crédito História da evolução normativa no Brasil. 6 ed. Brasília: BCB, 2008. 92 p.

PORTAL DO COOPERATIVISMO FINANCEIRO. Disponível em: http://cooperativismodecredito.coop.br/cooperativismo. Acesso em 30 de out de 2018.

RICCIARDI, L.; LEMOS, R. de J. Cooperativa, a empresa do século XXI: como os países em desenvolvimento podem chegar a desenvolvidos. São Paulo: LTr, 2000. 183 p.

RUA, O. L.; MELO, L. F. O papel da vantagem competitiva na relação entre internacionalização e desempenho das exportações: estudo de caso daEFACEC. Revista Ibero-Americana de Estratégia, v. 14, n. 1, p. 28-42, 2015. https://doi.org/10.5585/riae. v14i1.1995.

SANTOS, J. C. de L. Os 25 anos da retomada do Cooperativismo de Crédito Brasileiro. Porto Alegre: Imprensa Livre, 2005. p. 14.

SILVA, E. L.; MENEZES, E. M. Metodologia da pesquisa e elaboração de dissertação. 4. ed. Florianópolis, 2005. 
47 | A intercooperação nas cooperativas de crédito...

SINGER, P. Introdução à Economia Solidária. 4. reimpr. São Paulo: Editora Fundação Perseu Abramo, 2010. 127 p.

TRIVIÑOS, A. N. S. Introdução à pesquisa em Ciências Sociais: a pesquisa qualitativa em Educação. 17. reimpr. São Paulo: Atlas, 2008.

WOITCHUNAS, L. F. Redes Empresariais e Gestão da Qualidade Ijuí: Ed. Unijuí, 2009. 